\title{
Effects of Fermented Red Ginseng Extracts on Hyperglycemia in Streptozotocin-induced Diabetic Rats
}

\author{
Hyun-Jeong Kim ${ }^{1 *}$, In-Gyeong Chae ${ }^{2}$, Sung-Gyu Lee ${ }^{2,3}$, Hyun-Jin Jeong ${ }^{3}$, Eun-Ju Lee ${ }^{3}$, \\ and In-Seon Lee ${ }^{1,2}$ \\ ${ }^{1}$ The Center for Traditional Microorganism Resources, Keimyung University, Daegu 704-701, Korea \\ ${ }^{2}$ Department of Food and Technology, Keimyung University, Daegu 704-701, Korea \\ ${ }^{3}$ Bio Research Institute, NUC Electronics Co. Ltd., Daegu 702-053, Korea
}

Fermented red ginseng (FRG) was prepared by inoculating $0.1 \%$ Lactobacillus fermentum NUC-C1 and fermenting them at $40^{\circ} \mathrm{C}$ for 12 hours. The ginsenoside contents of FRG were increased compared with those of red ginseng (RG). Moreover, the levels of the ginsenosides Rg2, Rg3, and Rh2 in FRG increased significantly. In an oral glucose tolerance test (OGTT), blood glucose levels were lower in animals fed with RG and FRG extracts than in normal controls. In particular, FRG extracts in OGTT were superior to RG extracts. The antidiabetic effects of FRG in streptozotocin (STZ)-induced diabetic rats were investigated. Rats were divided into four groups: normal control, diabetes mellitus (DM), FRG administered at $100 \mathrm{mg} / \mathrm{kg}$, and FRG administered at $200 \mathrm{mg} / \mathrm{kg}$ groups. FRG extracts were orally administered to each treatment group for 3 weeks, and blood glucose, insulin, and lipid levels of each group were determined. Orally administered FRG extracts significantly reduced blood glucose levels and increased plasma insulin levels in diabetic rats. Additionally, the activities of disaccharidases, including sucrase, lactase, and maltase, were decreased significantly in the FRG groups. FRG groups also had reduced triglyceride and total cholesterol levels, compared with the DM group. These results suggest that FRG may have antidiabetic effects in STZ-induced diabetic rats.

Keywords: Red ginseng, Fermentation, Antidiabetic effect, Streptozotocin

\section{INTRODUCTION}

Diabetes mellitus is a metabolic disease characterized by hyperglycemia, resulting from a lack of insulin secretion by the pancreas or low biological activity of the insulin secreted, and is classified into insulin-dependent (type 1) and -independent types (type 2) [1]. Recently, the World Health Organization reported that the incidence of diabetes was estimated to be $170,000,000$ worldwide in the year 2000. However, this incidence is expected to rise to $360,000,000$ by the year 2030 . Moreover, the incidence of diabetes in Korea has rap- idly increased, because of poor diet and obesity $[2,3]$. The treatment of diabetes depends on insulin injections, diet, and exercise. Insulin injection, the major therapy for type 1 diabetes, can produce several side effects. Thus, to ameliorate diabetes, many studies have searched for active ingredients found in herbs [4-6]. Ingredients from medicinal herbs, beans, ginseng, and red ginseng, and their extracts have been shown to be efficacious in decreasing hyperglycemia, and subsequently, in ameliorating diabetes [7-10]. Among the different herbs, ginseng is the most efficacious for immune

(c) This is an Open Access article distributed under the terms of the Creative Commons Attribution Non-Commercial License (http://creativecommons.org/licenses/by-nc/3.0/) which permits unrestricted non-commercial use, distribution, and reproduction in any medium, provided the original work is properly cited.

Received 28 Jan. 2010, Revised 1 Apr. 2010, Accepted 11 Apr. 2010

*Corresponding author

E-mail: sarikhj@kmu.ac.kr

Tel: +82-53-580-6449, Fax: +82-53-580-6447 
stimulation, and the prevention of hyperlipidemia and diabetes [11-14]. Additionally, red ginseng, which is produced by steaming fresh ginseng, comprises modified saponin and amino acids, and sugar products. Thus, red ginseng is more efficacious for long-term storage [15-17]. The active ingredients in red ginseng are classified into saponin components (ginsenosides) and nonsaponin components (the polyacetylene compounds, panaxatriol and panaxadiol, acidic polysaccharides, and amino acids), and these ingredients are responsible for immune stimulation, and the prevention of diabetes, cancer, fatigue, stress, and hyperlipidemia [18-22].

Recently, microbial methods have been introduced for the transformation of medicinal herbs, and active ingredients generated by microbial transformation have been investigated [23]. In particular, the pharmacological effects of a new saponin generated by red ginseng fermentation and mass production have been reported [24]. Fermentation of red ginseng by intestinal microorganisms transforms saponins, such as Rb1, Rb2, Rc, and $\mathrm{Rd}$, into readily absorbed forms, such as compound $\mathrm{K}$, which is active in cancer, diabetes, and immune stimulation [25]. These results demonstrated that fermentation of red ginseng and medicinal herbs with microorganisms, such as lactic acid bacteria, transforms pharmacological ingredients into low-molecular-weight active compounds with higher absorption [24]. Additionally, fermentation reduces the toxicity of specific components and can degrade pesticides [23].

Diabetes was induced by treating animals with alloxan or streptozotocin (STZ), both of which produce several side effects, including liver and kidney dysfunction, and bone marrow destruction [26]. Because STZ has a lower toxicity than alloxan, STZ is generally used in rat models of diabetes [27].

In this study, red ginseng was prepared from white ginseng, and was further fermented with Lactobacillus fermentum NUC-C1. The anti-diabetic effects were determined following the oral administration of fermented red ginseng in STZ-induced diabetic rats, and body weight, blood glucose level, and other serological indicators were examined.

\section{MATERIALS AND METHODS}

\section{Samples}

The fermented red ginseng (FRG) used in this study was produced at the Bio Research Institute of NUC Electronics Co., Ltd. (Daegu, Korea). Referred to as 'NUC fermented red ginseng extracts powder,' it was prepared using the following procedure: $2 \mathrm{~L}$ of purified water was added to $300 \mathrm{~g}$ of 6-year-old white dried ginseng, purchased from Geumsan Insam Nong-hyup (Korea), and steamed for 24 hours. A further $4 \mathrm{~L}$ of distilled water was added, and the ginseng solution was steamed at $90^{\circ} \mathrm{C}$ for 48 hours to make red ginseng (RG) extracts. The RG extracts was then used to make FRG extracts by the addition of $0.1 \%$ Lactobacillus fermentum NUC-C1 (KCCM10929P) and 12 hours of fermentation at $40^{\circ} \mathrm{C}$. RG and FRG extracts were both dried in vacuo (Eyela, Tokyo Rikakikai Co., Tokyo, Japan), then freeze-dried and pulverized, and finally stored at $-20^{\circ} \mathrm{C}$ until needed for experiments.

\section{Ginsenoside content analysis}

After extraction of RG and FRG dried powders with $80 \%$ methanol, the products were dried in vacuo and dissolved in distilled water; then, the soluble constituents were removed by diethyl ether extraction. Watersaturated butanol was added to the remaining water layer, and crude saponin was prepared by concentrating the $n$-butanol layer. Crude saponin was again diluted with methanol, and then filtered and high-performance liquid chromatography (HPLC) analysis was performed using an X-Terra RP18 column $(4.6 \times 250 \mathrm{mM}$; Waters, Milford, MA, USA). For HPLC mobile phase analysis, acetonitrile and distilled water were combined in a ratio of 80:20, and the solution was used for elution. The flow rate was controlled at $1.0 \mathrm{~mL} / \mathrm{min}$, the sample infusion volume was $20 \mu \mathrm{L}$, the detection wavelength was $203 \mathrm{~nm}$, and the column temperature at $25^{\circ} \mathrm{C}$ for the analysis.

\section{Oral glucose tolerance test}

Blood glucose levels of normal rats that fasted for at least 12 hours were determined; then, rats were orally administered RG or FRG extracts dissolved in distilled water at $100 \mathrm{mg} / \mathrm{kg}$ or $200 \mathrm{mg} / \mathrm{kg}$, respectively. For the control group, an equal amount of normal saline was given. Subsequently, $40 \%$ glucose was orally administered to all groups at $1 \mathrm{~g} / \mathrm{kg}$, followed by blood collection from tail veins at 30,60, 90, and 120 minutes postglucose administration to observe changes in blood glucose levels.

\section{Induction of diabetes in experimental animals}

Sprague-Dawley rats (Orient Bio Inc., Seongnam, Korea) weighing $180 \pm 10 \mathrm{~g}$ were used. Cages were maintained at $23 \pm 2^{\circ} \mathrm{C}$, with a humidity of $60 \pm 5 \%$, and 12/12-h light/dark cycles. Rats were fed ad libitum with 
solid rat food and water for 1 week to adjust them to the environment; then, the rats were used in the subsequent 3 weeks, with close adherence to the university's ethical guidelines for animal experiments.

The animals were divided into one normal control group (NC) and three diabetes induction groups. The diabetes induction groups were further divided into diabetes control (DM) and FRG groups (FRG administered at $100 \mathrm{mg} / \mathrm{kg}$ [FRG100] and FRG administered at $200 \mathrm{mg} / \mathrm{kg}$ [FRG200]). Six rats were maintained for 3 weeks in each group. In terms of feeding, the $\mathrm{NC}$ and DM groups were fed only with the normal feedstuff, whereas the FRG groups were orally administered 100 or $200 \mathrm{mg} / \mathrm{kg}$ FRG extracts dissolved in water, at 10 a.m. daily. The sample concentration was determined in preliminary experiments, and during the experiments, food and water were given ad libitum, and the room was maintained under 12/12-h light/dark conditions. Rats that had undergone a 1-week adjustment period for diabetes induction were fasted for at least 12 hours, and peritoneal injection of streptozotocin, diluted in $0.01 \mathrm{M}$ citrate buffer, was given at $60 \mathrm{mg} / \mathrm{kg}$. In the $\mathrm{NC}$ group, the same concentration of normal saline was used for the peritoneal injection. Blood collected from tail veins was used to confirm diabetes induction, and rats with fasting blood glucose levels above $300 \mathrm{mg} / \mathrm{dL}$ were used in experiments.

\section{Weight and feed intakes}

The increase in body weight was measured at the same time each week for the 3-week period of the study. The feed intakes were recorded by measuring the remaining feedstuff every 3 days, and subtracting that amount from the feedstuff originally provided.

\section{Blood glucose level and biochemical analysis}

Changes in blood glucose levels during the feeding period were measured weekly using a blood glucose monitoring system (ACCU-CHEK Sensor; Roche Diagnostics $\mathrm{GmbH}$, Mannheim, Germany), and blood that was collected from rat tail veins after fasting the rats for over 12 hours. At the end of the 3-week feeding period, the rats that were fasted for 12 hours were anesthetized and dissected. Blood was collected from peritoneal veins using heparin-treated syringes, and, after letting the blood samples stand for 30 minutes, they were centrifuged to separate the plasma. The liver, spleen, kidneys, pancreas, and small intestine were also removed, washed with phosphate-buffered saline, depleted of moisture, and then weighed. Separated plasma and tis- sues were snap-frozen in liquid nitrogen, and kept at $-70^{\circ} \mathrm{C}$ until analyzed. Analysis of the diabetic marker insulin was performed using an insulin kit (Rat Insulin ELISA; Mercodia, Uppsala, Sweden), and from the separated plasma, triglyceride levels, total cholesterol content, and high density lipoprotein (HDL) cholesterol content were measured using a triglyceride measuring kit, a total cholesterol content measuring kit (Asan Pharmaceutical, Whasung, Korea), and an HDL cholesterol measuring kit (Asan Pharmaceutical), respectively.

\section{Small intestinal disaccharidase measurements}

Mucosal samples obtained from the small intestines were thawed at room temperature and a four-fold greater amount of distilled water was added to them, followed by homogenization with a homogenizer. Based on Dahlqvist's methods [28], maltose, sucrose, and lactose were used as substrates, and activation of disaccharide hydrolytic enzymes, such as maltase, sucrase, and lactase, were quantified. Glucose that was produced from the enzymatic reactions was oxidized into gluconic acid and $\mathrm{H}_{2} \mathrm{O}_{2}$ by glucose oxidase, and then $\mathrm{H}_{2} \mathrm{O}_{2}$ reacted with peroxidase to form a colored product, which was measured. Activation of a disaccharide hydrolytic enzyme is represented as units/g protein (specific activity) after setting 1 unit as $1 \mu$ mole of glucose produced by the enzyme in 1 minute.

\section{Statistical analysis}

The means and standard deviations of the data were calculated. Evaluation of each group's significance was performed using the SAS ver. 8 (SAS Institute, Cary, NC, USA) at a 5\% significance level, using Duncan's multiple range tests.

\section{RESULTS AND DISCUSSION}

\section{Comparison of ginsenoside contents in RG and FRG}

As shown in Table 1, FRG, for which Lactobacillus fermentum NUC-C1 was used in the fermentation process, contained more ginsenoside types than RG. Additionally, FRG had a significant increase in the ginsenosides Rg2, Rg3, and Rh2, with 95.11\% Rg3. This result indicated that ginsenosides were degraded into non-glycosides, such as Rg3, by the fermentation [29]. In ginseng, diol-type saponins, such as ginsenoside $\mathrm{Rb} 1, \mathrm{Rb} 2, \mathrm{Rc}, \mathrm{Rd}, \mathrm{Rg} 3$, and Rh2, exhibit anti-diabetic activity [30], and ginsenoside Rh2 increases insulin secretion in STZ-induced diabetic rats to decrease the 
Table 1. Ginsenoside contents of red ginseng (RG) and fermented red ginseng (FRG)

\begin{tabular}{ccc}
\hline \multirow{2}{*}{ Ginsenoside } & \multicolumn{2}{c}{ Contents $(\mathrm{mg} \%)$} \\
\cline { 2 - 3 } & $\mathrm{RG}$ & $\mathrm{FRG}^{\mathrm{l}}$ \\
\hline $\mathrm{Rb} 1$ & - & 0.14 \\
$\mathrm{Rb} 2$ & - & 0.09 \\
$\mathrm{Rb} 3$ & - & 0.07 \\
$\mathrm{Rc}$ & - & 0.13 \\
$\mathrm{Rd}$ & 0.30 & 0.32 \\
$\mathrm{Re}$ & 1.86 & 0.01 \\
$\mathrm{Rg} 1$ & 1.45 & 0.01 \\
$\mathrm{Rg} 2$ & 1.62 & 12.6 \\
$\mathrm{Rg} 3$ & 23.62 & 95.11 \\
$\mathrm{Rh} 1$ & 26.02 & 16.41 \\
Rh2 & - & 2.57 \\
Compound-K & - & Trace \\
\hline
\end{tabular}

${ }^{1)} \mathrm{FRG}$ fermented with Lactobacillus fermentum NUC-C1 at $40^{\circ} \mathrm{C}$ for 12 hours.

blood glucose concentration [31]. Thus, we hypothesized that the greater increase in these components in FRG compared with RG would enhance the antidiabetic activity of FRG in this study. Furthermore, it has been reported that following fermentation of $R G$, the metabolized products of saponin are converted by intestinal bacteria into compound $\mathrm{K}$, which is readily absorbed in the body. Compound $\mathrm{K}$ possesses anti-diabetic properties [25], and, in this study, it was detected in FRG in small quantities. Although, in comparison with RG, FRG had lower levels of the ginsenosides Re and Rg1, which exhibit anti-diabetic effects [32], FRG enhances anti-diabetic activities through its greater number of ginsenoside types and the level of their content, resulting in their complex effects.

\section{Oral glucose tolerance in RG and FRG}

Oral glucose tolerance tests of manufactured RG and FRG extracts demonstrated the highest blood glucose level at 30 minutes following glucose administration, with decreasing blood glucose levels thereafter (Fig. 1). Compared with the group that was administered glucose alone, without sample administration, the RG and FRG groups showed a significant reduction in blood glucose levels. Additionally, at 30 minutes following glucose administration, the $200 \mathrm{mg} / \mathrm{kg} \mathrm{RG}$ and FRG groups had a greater drop in blood glucose levels than the $100 \mathrm{mg} / \mathrm{kg}$ groups. At 60 minutes post-glucose administration, the blood glucose levels in the FRG groups were reduced by more than in the RG groups;

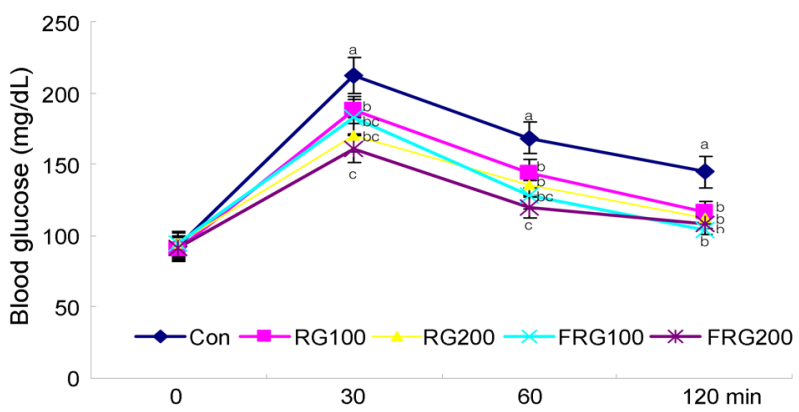

Fig. 1. Effects of red ginseng (RG) and fermented red ginseng (FRG) extracts in oral glucose tolerance tests (OGTT) in rats. In the OGTT, glucose levels were estimated following the oral administration of $1 \mathrm{~g} / \mathrm{kg} \mathrm{D(+)-}$ glucose at the indicated time points. con $(n=6)$, normal control group; RG100 ( $n=6)$, the diabetic group fed with $100 \mathrm{mg} / \mathrm{kg}$ of RG extracts; RG200 $(n=6)$, the diabetic group fed with $200 \mathrm{mg} / \mathrm{kg}$ of RG extracts; FRG100 ( $n=6)$, the diabetic group fed with $100 \mathrm{mg} / \mathrm{kg}$ of FRG extracts; FRG2100 ( $n=6)$, the diabetic group fed with $200 \mathrm{mg} / \mathrm{kg}$ of FRG extracts. Mean values with different superscripts in the same column are significantly different $(p<0.05)$.

the reduction was significant in the $200 \mathrm{mg} / \mathrm{kg}$ FRG group. At 120 minutes post-glucose administration, the blood glucose level was reduced to almost the level before fasting, regardless of the sample concentration used, and no significant difference between the samples was observed. In summary, as the concentration of RG and FRG in the samples increased, the blood glucose level decreased, and the degree of reduction was greater with FRG than RG. This may be because of the fermentation factors created by the Lactobacillus used in the process of RG fermentation, and their suppressive effects on rising blood glucose levels. Thus, in this study we demonstrated the effects of FRG in the improvement of glucose metabolism.

\section{Changes in body and organ weights}

Changes in body weight of the rats with STZ-induced diabetes are shown in Fig. 2 after feeding for 3 weeks plus orally administered FRG extracts. In contrast to the steady increase in body weight in the NC group over time, the DM group had decreasing body weights, because of STZ. Although the body weight of the FRG extracts-administered group decreased more than the normal group, it was still significantly higher, compared with the body weight of the DM group. However, no significant difference in weight between groups receiving different FRG concentrations was observed.

STZ administration causes $\beta$-cell destruction within the pancreas, leading to type 1 diabetes mellitus, and consequently insulin production deficiency and a decline in insulin action. Insufficiency in energy production from glucose metabolism affects growth and develop- 
ment [27]. Insulin is involved in protein metabolism and stimulates the influx of amino acids into skeletal muscles to increase protein synthesis activity. In animals with induced diabetes, the decline in such actions of insulin leads to the decline in cellular glucose utilization and a starvation state [33]. This is why all the diabetic groups had greater weight reductions than the normal group. Moreover, the average daily dietary consumption of all the experimental groups was significantly higher than the NC group (Table 2), which was attributed to diabetic symptoms (i.e., polyphagia, polyuria, and polydipsia). When the feed intakes of the DM group $(40.0 \pm 1.5 \mathrm{~g} / \mathrm{day} / \mathrm{rat})$ was compared with that of the NC group (24.6 $\pm 0.5 \mathrm{~g} /$ day/rat), that of the DM group increased significantly, by more than two-fold. Conversely, in the $200 \mathrm{mg} / \mathrm{kg}$ FRG group, feed intakes decreased significantly compared with the DM group. In this study, the weight of the DM group decreased continuously, despite high dietary consumption, and this may be because of regressive changes in body metabolism pathways caused by diabetes. However, in terms of changes in organ weight/body weight (Table 2), the weight of the pancreas and kidneys in the DM group increased

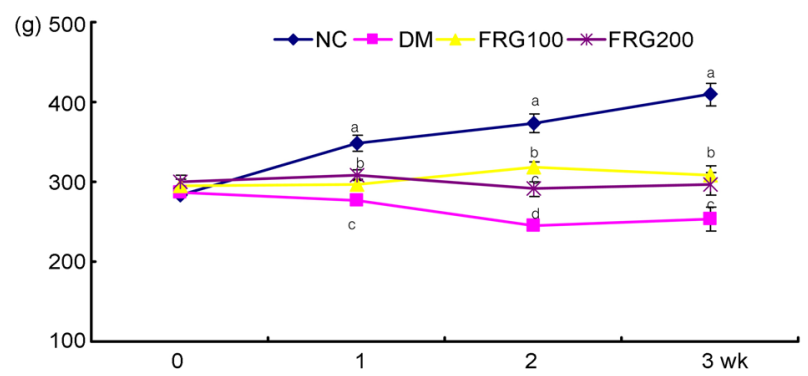

Fig. 2. Effects of fermented red ginseng (FRG) extracts on body weight in streptozotocin-induced diabetic rats. NC $(n=6)$, normal control group; DM $(n=6)$, diabetic mellitus group; FRG100 $(n=6)$, diabetic group fed with $100 \mathrm{mg} / \mathrm{kg}$ of FRG extracts; FRG200 ( $n=6)$, diabetic group fed with 200 $\mathrm{mg} / \mathrm{kg}$ of FRG extracts. Mean values with different superscripts in the same column are significantly different $(p<0.05)$. more than that in the $\mathrm{NC}$ group, while in the FRG group, the weight of the pancreas and kidneys seemed to decrease overall, but with no significant difference compared with the DM group. The spleen weight was not significantly different between the groups.

\section{Changes in blood glucose concentration}

Changes in blood glucose levels are shown in Fig. 3. Blood glucose levels increased significantly in the DM group, compared with the NC group, and although no difference between the DM and FRG groups before sample administration was observed, the FRG groups showed significantly reduced blood glucose levels from 1 week after sample administration, compared with the DM group. Blood glucose levels decreased more significantly with increasing duration of the feeding period, and at 2 and 3 weeks after sample administration, the $100 \mathrm{mg} / \mathrm{kg}$ FRG group had a more significant reduction in blood glucose levels, compared with the $200 \mathrm{mg} / \mathrm{kg}$ FRG group. The DM group had a greater increase in blood glucose levels compared with the $\mathrm{NC}$ group, because of the side effects of peritoneal injection of STZ, which include pancreatic $\beta$-cell destruction and inhibition of insulin secretion. However, because FRG decreases the blood glucose level, the FRG may have effects in the control of blood glucose levels. Moreover, when $100-200 \mathrm{mg} / \mathrm{kg}$ FRG was administered to the normal group, the blood glucose levels of each group did not differ significantly (data not shown). Thus, FRG had little influence on changes in the blood glucose level in normal animals.

Studies have demonstrated that STZ-induced rats fed with a diet containing tissue cultured ginseng powder decreased blood glucose levels [34], and red ginseng lowered the blood glucose level in hyperglucosemia induced by STZ [35]. This study also demonstrated blood glucose-lowering effects of FRG in rats with STZ-induced diabetes. Importantly, the $100 \mathrm{mg} / \mathrm{kg}$ FRG group

Table 2. Effects of fermented red ginseng (FRG) extracts on feed intakes and organ weight in streptozotocin (STZ)-induced diabetic rats for 3 weeks

\begin{tabular}{lccccc}
\hline & $\begin{array}{c}\text { Feed intakes } \\
(\mathrm{g} / \text { day })\end{array}$ & \multicolumn{3}{c}{ Organ weight $(\%)$} \\
\cline { 3 - 6 } & $24.60 \pm 0.47^{\mathrm{c}}$ & $2.95 \pm 0.16^{\mathrm{b}}$ & $0.16 \pm 0.03^{\mathrm{ns}}$ & $0.61 \pm 0.03^{\mathrm{c}}$ & Pancreas $^{\mathrm{n}}$ \\
\hline NC & $40.04 \pm 1.52^{\mathrm{b}}$ & $4.39 \pm 0.33^{\mathrm{a}}$ & $0.15 \pm 0.04$ & $1.13 \pm 0.15^{\mathrm{a}}$ & $0.52 \pm 0.01^{\mathrm{b}}$ \\
DM & $43.60 \pm 1.93^{\mathrm{b}}$ & $4.19 \pm 0.30^{\mathrm{a}}$ & $0.20 \pm 0.04$ & $1.04 \pm 0.15^{\mathrm{b}}$ & $0.46 \pm 0.09^{\mathrm{b}}$ \\
FRG100 & $44.57 \pm 0.41^{\mathrm{a}}$ & $4.33 \pm 0.23^{\mathrm{a}}$ & $0.16 \pm 0.04$ & $1.04 \pm 0.09^{\mathrm{a}}$ & $0.48 \pm 0.02^{\mathrm{a}}$
\end{tabular}

Mean values with different superscripts in the same column are significantly different $(p<0.05)$.

NC $(n=6)$, normal control group; DM $(n=6)$, diabetic mellitus group; FRG100 ( $n=6)$, diabetic group fed with $100 \mathrm{mg} / \mathrm{kg}$ of FRG extracts; FRG200 $(n=6)$, diabetic group fed with $200 \mathrm{mg} / \mathrm{kg}$ of FRG extracts. 


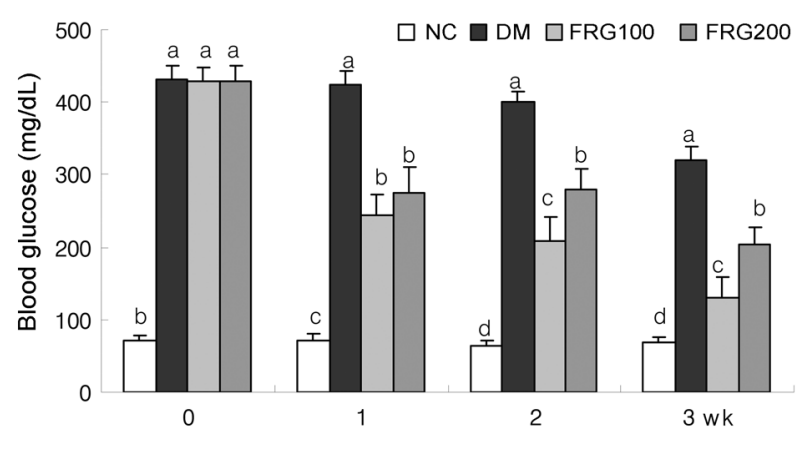

Fig. 3. Changes in the blood glucose levels during the 3-week period in streptozotocin-induced diabetic rats after fermented red ginseng (FRG) extracts administration. NC $(n=6)$, normal control group; DM $(n=6)$, diabetic mellitus group; FRG100 ( $n=6)$, diabetic group fed with $100 \mathrm{mg} / \mathrm{kg}$ of FRG extracts; FRG200 ( $n=6)$, diabetic group fed with $200 \mathrm{mg} / \mathrm{kg}$ of FRG extracts. Mean values with different superscripts in the same column are significantly different $(p<0.05)$.

demonstrated a significant reduction in blood glucose levels.

\section{Changes in plasma insulin concentration}

The plasma insulin concentration was $24.56 \mathrm{ng} / \mathrm{mL}$ in the $\mathrm{NC}$ group and $6.58 \mathrm{ng} / \mathrm{mL}$ in the $\mathrm{DM}$ group, with the NC group showing a more significant increase in plasma insulin concentrations than the DM group. While the FRG groups had a more significant increase in insulin concentration than the DM group, no significant difference between the groups at different FRG concentrations was observed (Table 3). This may be attributable to the decrease in insulin secretion because of STZ-induced pancreatic $\beta$-cell destruction, followed by FRG sample administration, which helped the pancreatic cells to recover and increase the plasma insulin concentration [26]. The $100 \mathrm{mg} / \mathrm{kg}$ FRG group had a greater reduction in blood glucose levels than the 200 $\mathrm{mg} / \mathrm{kg}$ FRG group, because of the greater increase in the insulin concentration of the $100 \mathrm{mg} / \mathrm{kg}$ FRG group, leading to a greater reduction in blood glucose levels. Thus, the FRG sample and its ability to reduce the blood glucose level were used to illustrate that the increase in insulin concentration significantly affected the blood glucose level.

\section{Inhibition of small intestinal disaccharidase ac- tivity}

In comparison with the $\mathrm{NC}$ group, the DM group had a significant increase in disaccharidase activity, and the FRG groups had a significantly decreased disaccharidase activity, compared with the DM group (Fig. 4). Moreover, the $100 \mathrm{mg} / \mathrm{kg}$ FRG group showed a more significant inhibition of disaccharidase activity than the $200 \mathrm{mg} / \mathrm{kg}$ FRG group. This was in agreement with the results that the $100 \mathrm{mg} / \mathrm{kg}$ FRG group had a more significantly increased insulin concentration than the 200 $\mathrm{mg} / \mathrm{kg}$ FRG group, thereby significantly decreasing the blood glucose level.

Generally, in animal models with STZ-induced diabetes, morphological, functional, and metabolic substitution take place in the small intestine, with an increase in small intestinal disaccharidase activity to stimulate glucose absorption there [36]. In this study, an increase in disaccharidase activity in the DM group was observed following FRG administration and a subsequent decline in enzyme activities and suppression of blood glucose level increase. Thus, FRG fermented by Lactobacillus may be an excellent candidate to inhibit disaccharidase activity and lower blood glucose levels.

\section{Changes in plasma lipid concentrations}

Following FRG administration, the total plasma cholesterol concentration was $60.29 \pm 5.65 \mathrm{mg} / \mathrm{dL}$ in the $\mathrm{NC}$ group, compared with $92.86 \pm 4.03 \mathrm{mg} / \mathrm{dL}$ in the $\mathrm{DM}$ group, a significant difference. The plasma cholesterol concentration in the FRG groups decreased, compared with that in the DM group. In terms of the $100 \mathrm{mg} / \mathrm{kg}$ FRG group, the plasma cholesterol concentration was $78.07 \pm 8.59 \mathrm{mg} / \mathrm{dL}$, which was significantly lower than in the DM group (Table 3). The increase in the total

Table 3. Effects of fermented red ginseng (FRG) extracts on plasma insulin, total cholesterol, high density lipoprotein (HDL)-cholesterol and triglyceride contents in streptozotocin-induced diabetic rats for 3 weeks

\begin{tabular}{lcccc}
\hline & $\begin{array}{c}\text { Insulin } \\
(\mathrm{ng} / \mathrm{mL})\end{array}$ & $\begin{array}{c}\text { Total cholesterol } \\
(\mathrm{mg} / \mathrm{dL})\end{array}$ & $\begin{array}{c}\text { HDL-cholesterol } \\
(\mathrm{mg} / \mathrm{dL})\end{array}$ & $\begin{array}{c}\text { Triglyceride } \\
(\mathrm{mg} / \mathrm{dL})\end{array}$ \\
\hline NC & $24.56 \pm 1.80^{\mathrm{a}}$ & $60.29 \pm 5.65^{\mathrm{c}}$ & $60.54 \pm 6.14^{\mathrm{b}}$ & $53.57 \pm 5.5^{\mathrm{bc}}$ \\
DM & $6.58 \pm 0.51^{\mathrm{c}}$ & $92.86 \pm 4.03^{\mathrm{a}}$ & $63.11 \pm 8.9^{\mathrm{ab}}$ & $104.47 \pm 4.48^{\mathrm{a}}$ \\
FRG100 & $10.4 \pm 1.08^{\mathrm{b}}$ & $78.07 \pm 8.59^{\mathrm{b}}$ & $73.30 \pm 12.7^{\mathrm{a}}$ & $51.64 \pm 4.58^{\mathrm{c}}$ \\
FRG200 & $8.56 \pm 1.14^{\mathrm{b}}$ & $84.50 \pm 6.64^{\mathrm{ab}}$ & $78.16 \pm 9.04^{\mathrm{a}}$ & $63.28 \pm 6.10^{\mathrm{b}}$ \\
\hline
\end{tabular}

Mean values with different superscripts in the same column are significantly different $(p<0.05)$.

$\mathrm{NC}(n=6)$, normal control group; DM $(n=6)$, diabetic mellitus group; FRG100 (n=6), diabetic group fed with $100 \mathrm{mg} / \mathrm{kg}$ of FRG extracts; FRG200 $(n=6)$, diabetic group fed with $200 \mathrm{mg} / \mathrm{kg}$ of $\mathrm{FRG}$ extracts. 

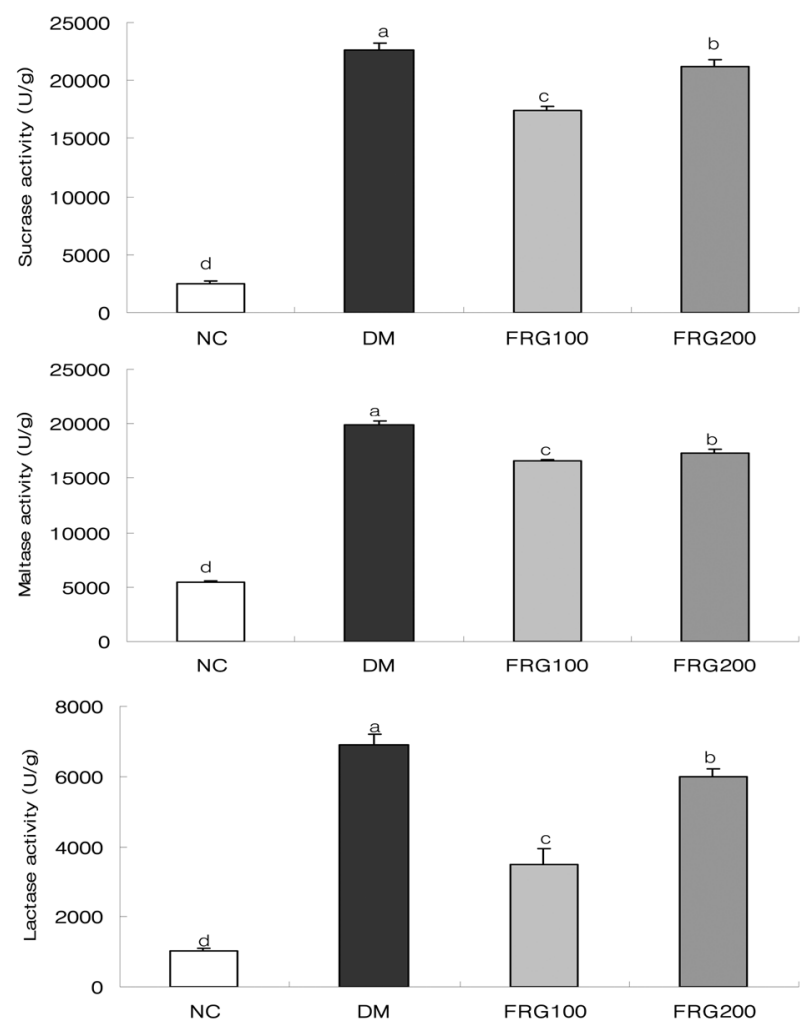

Fig. 4. Inhibitory effects of fermented red ginseng (FRG) extracts on disaccharidase activity in streptozotocin-induced diabetic rats. NC $(n=6)$, normal control group; DM $(n=6)$, diabetic mellitus group; FRG100 $(n=6)$, diabetic group fed with $100 \mathrm{mg} / \mathrm{kg}$ of FRG extracts; FRG200 ( $n=6)$, diabetic group fed with $200 \mathrm{mg} / \mathrm{kg}$ of FRG extracts. Mean values with different superscripts in the same column are significantly different $(p<0.05)$.

cholesterol level in the diabetes-induced group may be because of the inability of the rats to metabolize carbohydrates as an energy source, and the subsequent use of free fatty acids for energy and cholesterol synthesis [37]. Moreover, in a state of difficulty controlling glucose, a reduction in the activity of liver HMG-CoA reductase and an increase in the activity of intestinal HMG-CoA reductase occur, resulting in hypercholesterolemia [38]. Plasma HDL cholesterol increased more in the FRG groups than in the DM group, but not statistically significantly. Plasma HDL cholesterol was more significantly elevated in all the diabetic-induced groups, compared with the NC group. This observation was consistent with a report demonstrating that HDL cholesterol increased in the diabetes-induced group because of an increase in the total cholesterol level, and that in experiments with puffed RG, the HDL cholesterol level was also higher in the diabetes-induced group, compared with the normal group [38].

The plasma triglyceride concentration increased significantly, from $53.57 \pm 5.50 \mathrm{mg} / \mathrm{dL}$ in the $\mathrm{NC}$ group to $104.47 \pm 4.48 \mathrm{mg} / \mathrm{dL}$ in the DM group, while it decreased significantly in the FRG groups. In hyperlipidemia, a major complication of diabetes, the rate at which plasma fatty acids become triglycerides is greater than normal, leading to an increase in the plasma triglyceride concentration [39]. The triglyceride concentration in diabetes also increased in this study, and the $100 \mathrm{mg} / \mathrm{kg}$ FRG group showed a significant decrease in the plasma triglyceride concentration, compared with the NC group. This result is consistent with a report that revealed that saponin components in ginseng stimulated the decline and excretion of plasma cholesterol, and improved lipid metabolism with treatment with either tissue cultured ginseng or puffed RG $[33,40]$.

In summary, FRG, RG fermented by Lactobacillus, demonstrated blood glucose-lowering effects in oral glucose tolerance test, and increased insulin secretion that was reduced because of pancreatic $\beta$-cell destruction, caused by STZ administration. Consequently, the blood glucose levels decreased. Additionally, FRG plays a role in improving glucose metabolism and lipid metabolism by decreasing the plasma triglyceride concentration.

\section{ACKNOWLEDGEMENTS}

This work is supported by Regional Industry Technology Development project in year 2008 (Project No. 70002701) and by Center for Traditional Microorganism Resources, Keimyung University under the support of Ministry of Knowledge and Economy.

\section{REFERENCES}

1. George P, Ludvik B. Lipids and diabetes. J Clin Basic Cardiol 2000;3:159-162.

2. Park YM, Sohn CM, Jang HC. A study on status and subjective recognition of functional foods among diabetic patients. J Korean Diet Assoc 2005;11:216-222.

3. Korea National Statistical Office. The cause of death statistics 2008: 2009 annual report on the cause of death statics. [accessed Mar 15, 2010]. Available from: http://kostat. go.kr/board_notice/BoardAction.do?method=view\&board id $=144 \&$ seq $=85 \&$ num $=85 \&$ parent_num $=0$.

4. Choi JS, Chung HY, Han SY. A preliminary study on hypercholesterolemic and hyperglycemic activities of some medical plants. Korean J Pharm 1990;21:153-157.

5. Kim TH, Yang KS, Whang SH. Studies on the physiochemical activities of Commelinae herba extract on the 
normal and streptozotocin-induced hyperglycemic rats. SM Pharm Sci 1990;7:39-59.

6. Lim SJ, Kim SY, Lee JW. The effects of Korean wild vegetables on blood glucose levels and liver-muscle metabolism of stretozotocin-induced diabetic rats. Korean J Nutr 1995;28:585-594.

7. Rho MH, Choi MA, Koh JB. Effects of raw soy flour (yellow and black) on serum protein concentrations and enzyme activity in streptozotocin-diabetic rats. J Korean Soc Food Sci Nutr 1998;27:724-730.

8. Choi MJ. Comparison of dietary casein or soy protein effect on plasma glucose, lipids, and hormone concentrations in the streptozotocin-induced diabetic rats. J Res Inst Life Sci 1997;23:285-295.

9. Park KS, Ko SK, Chung SH. Comparisons of antidiabetic effect between Ginseng Radix Alba, Ginseng Radix Rubra and Panax Quinquefoli Radix in MLD STZ-induced diabetic rats. J Ginseng Res 2003;27:56-61.

10. Kim HS, Seong YH, Yang JW, Jeon BS, Park UY, Park WK, Oh KW, Choi KJ. Hypoglycemic effects of extract mixture of red ginseng and steamed RehManiae radix on streptozotocin-induced diabetic rats. Korean J Ginseng Sci 1997;21:169-173.

11. Lim SJ, Han HK, Ko JH. Effects of edible and medicinal plants intake on blood glucose, glycogen and protein levels in streptozotocin induced diabetic rats. Korean $\mathrm{J}$ Nutr 2003;36:981-989.

12. Attele AS, Wu JA, Yuan CS. Ginseng pharmacology: multiple constituents and multiple actions. Biochem Pharmacol 1999;58:1685-1693.

13. Yoon SH, Joo CN. Study on the preventive effect of ginsenosides against hypercholesterolemia and its mechasnism. Korean J Ginseng Sci 1993;17:1-12.

14. Woo KS, Kim CM, Koo KH. An experimental study on the effect of ginseng saponin upon diabetes mellitus. Hanyang J Med 1982;2:47-57.

15. Kim EM. Quality characteristics of jeung-pyun according to the level of red ginseng powder. Korean J Food Cookery Sci 2005;21:209-216.

16. Ko SK, Lee CR, Choi YE, Im BO, Sung JH, Yoon KR. Analysis of ginsenosides of white and red ginseng concentrates. Korean J Food Sci Technol 2003;35:536-539.

17. Kim ND. Pharmacological effects of red ginseng. J Ginseng Res 2001;25:2-10.

18. Lee BJ, Heo H, Oh SC, Lew JH. Comparison study of Korean and Chinese ginsengs on the regulation of lymphocyte proliferation and cytokine production. J Ginseng Res 2008:32:250-256.

19. Kim US, Koh HK, Kang SK. Study of the effects of different products of ginseng radix aqua-acupuncture on the alloxan-induced diabetic rats. J Korean Acupunct Moxibust Soc 1989;6:1-13.

20. Yun TK, Lee YS, Lee YH, Yun HY. Cancer chemopreventive compounds of red ginseng produced from Panax ginseng C.A. Meyer. J Ginseng Res 2001;25:107-111.

21. Kim DJ, Seong KS, Kim DW, Ko SR, Chang CC. Antioxidative effects of red ginseng saponins of paraquat-induced oxidative stress. J Ginseng Res 2004;28:5-10.

22. Lee CK, Choi JW, Kim H, Han YN. Biological activities of acidic polysaccharide of Korean red ginseng. II. Effects on hyperlipidemia induced by alcohol. J Ginseng Res 1999;23:8-12.

23. Bae EA, Han MJ, Kim EJ, Kim DH. Transformation of ginseng saponins to ginsenoside $\mathrm{Rh} 2$ by acids and human intestinal bacteria and biological activities of their transformants. Arch Pharm Res 2004;27:61-67.

24. Trinh HT, Han SJ, Kim SW, Lee YC, Kim DH. Bifidus fermentation increases hypolipidemic and hypoglycemic effects of red ginseng. J Microbiol Biotechnol 2007;17:1127-1133.

25. Bae EA, Park SY, Kim DH. Constitutive beta-glucosidases hydrolyzing ginsenoside $\mathrm{Rb} 1$ and $\mathrm{Rb} 2$ from human intestinal bacteria. Biol Pharm Bull 2000;23:14811485.

26. Sathishsekar D, Subramanian S. Beneficial effects of Momordica charantia seeds in the treatment of STZinduced diabetes in experimental rats. Biol Pharm Bull 2005;28:978-983.

27. Liu Z, Li J, Zeng Z, Liu M, Wang M. The antidiabetic effects of cysteinyl metformin, a newly synthesized agent, in alloxan- and streptozotocin-indued diabetic rats. Chemico-Biological Interactions 2008;173:68-75.

28. Dahlqvist A. Assay of intestinal disaccharidases. Anal Biochem 1968;22:99-107.

29. Quan LH, Liang Z, Kim HB, Kim SH, Kim SY, Noh YD, Yang DC. Conversion of ginsenoside Rd to compound $\mathrm{K}$ by crude enzymes extracted from Lactobacillus brevis LH8. J Ginseng Res 2008;32:226-231.

30. Suda K, Murakami K, Murata Jun, Hasegawa H, Saiki IL. An intestinal bacterial metabolite (M1) of ginseng protopanaxadiol saponins inhibits tumor-induced neovascularization. J Tradit Med 2000;17:144-150.

31. Lai DM, Tu YK, Liu IM, Chen PF, Cheng JT. Mediation of beta-endorphin by ginsenoside Rh2 to lower plasma glucose in streptozotocin-induced diabetic rats. Planta Med 2006;72:9-13.

32. Kim DH. Metabolism of ginsenosides to bioactive compounds by intestinal microflora and its industrial application. J Ginseng Res 2009;33:165-176.

33. Park HR, Cho JS. Effect of natural medicinal plants- 
extracts on organ weight and blood glucose challenge in Streptozotocin-induced diabetic rats. J Nat Sci 2006;25: 43-53.

34. Lee IS, Lee S, Lee IZ. Effects of tissue cultured ginseng on blood glucose and lipids in streptozotocin-induced diabetic rats. Korean J Food Sci Technol 2003;35:280285.

35. Kim HS, Seong YH, Yang JW, Jeon BS, Park UY, Park WK, Oh KW, Choi KJ. Hypoglycemic effects of extract mixture of red ginseng and steamed RehManiae Radix on streptozotocin-induced diabetic rats. Korean J Ginseng Sci 1997;21:169-173.

36. Adachi T, Mori C, Sakurai K, Shihara N, Tsuda K, Yasuda K. Morphological changes and increased sucrase and isomaltase activity in small intestines of insulindeficient and type 2 diabetic rats. Endocr J 2003;50:271279.
37. Yao HT, Huang SY, Chiang MT. A comparative study on hypoglycemic and hypocholesterolemic effects of high and low molecular weight chitosan in streptozotocin-induced diabetic rats. Food Chem Toxicol 2008;46:15251534.

38. O’Meara NM, Devery RA, Owens D, Collins PB, Johnson AH, Tomkin GH. Cholesterol metabolism in alloxan-induced diabetic rabbits. Diabetes 1990;39:626-633.

39. Kim SH, Kang JS, Lee SJ, Chung YJ. Antidiabetic effect of Korean red ginseng by puffing process in streptozotocin-induced diabetic rats. J Korean Soc Food Sci Nutr 2008;37:701-707.

40. Kim MW. Effects of Salicornia herbacea L. supplementation on blood glucose and lipid metabolites in streptozotocin-induced diabetic rats. Korean J Nutr 2007;40:513. 